\title{
Editorial
}

\section{Additional techniques in serous effusions}

\author{
A.G.J.M. Hanselaar \\ Department of Pathology, University Medical Center Nijmegen, The Netherlands
}

\begin{abstract}
Cytological examination is a valuable diagnostic tool in case of a serous effusion. The first manifestation of malignancy may be an effusion of the pleural, pericardial, or peritoneal cavity, especially in carcinoma of the ovary, or lung, and malignant mesothelioma. In other malignancies effusions may occur in the course of the disease. The contribution by Motherby et al. in this issue of ACP focuses on the contribution of image and flow cytometry to establish the presence or absence of malignancy in serous effusions [16]. They point out that the sensitivity of DNA image cytometry in equivocal effusions may be as high as $87.5 \%$, and that for the detection of malignancy, DNA image cytometry is superior to flow cytometry.
\end{abstract}

\section{Introduction}

The body cavities have visceral and parietal linings, enabling "free" movement of enclosed organs. These surfaces are covered by mesothelium, a single layer of polygonal or flattened mesothelial cells $[13,17]$. Serous fluid in the body cavities originates from subserosal vessels, and is removed by lymph vessels. Typically in the absence of pathology little serous fluid is present [25]. A quantity of serous fluid sufficient of tapping, indicates a pathologic process in the body cavities. The amount of serous fluid is influenced by the permeability of vessels, hydrostatic pressure, lymph drainage disturbances, colloid-osmotic pressure, and by secretion of tumors. An increased amount of serous fluid may be either a transudate (low protein content), due to infiltration of blood serum across the physically intact vascular wall, or an exsudate (high protein content), due to active accumulation of fluid apparently associated with damage of walls of capillaries. If the effusion is transudative, therapy is mostly directed toward the underlying cause, e.g., congestive heart failure, or cirrhosis [17]. If the effusion is exsudative, attempts will be made to define the etiology, e.g., inflammatory processes or tumors. The diagnosis of malignancy in serous effusions is mostly established via cytology.

Cells which may be present in serous fluids are mesothelial cells, macrophages, erythrocytes, lymphocytes, neutrophylic and eosinophylic granulocytes, and malignant cells. A proliferation of mesothelial cells can be caused by an inflammatory process of the serosa, presence of foreign body material, malignancy, and in a longstanding fluid. Reactive mesothelial cells easily desquamate into the serous fluid. The number of proliferating mesothelial cells may be high in chronic inflammation, carcinoma, trauma, lung infarction, processes with necrosis, and mesothelioma. A proliferation of mesothelial cells may be very hard to distinguish from malignant cells by routine cytological examination.

\section{Effusions in malignancy}

Malignant cells in serous effusions may be found in patients with primary tumors (malignant mesothelioma) or with secondary tumors (carcinomas, sarcomas and lymphomas). Malignant mesothelioma, known for the causal relationship with asbestos, is rare, has a very long latention period of 25-40 yrs, and a bad prognosis with a survival rate after 2 years of $20 \%$. In men metastatic cancers in pleural effusion are mostly carcinomas of the lung, lymphomas/leukemias, and stomach; in ascites it concerns mostly tumors of the stomach, pancreas, and lymphomas/leukemias. In women metastatic cancers in pleural effusion are mostly of the breast, lymphomas/leukemias, ovary, stomach, and lung; in ascites it concerns mostly tumors of the ovary, breast, and stomach [17].

It is of importance to realize that in most cases of malignancy always two types of "atypical" cells are present in the effusion: reactive proliferating mesothe- 
lial cells and a population of tumor cells. An exception when only solitary tumor cells are present is lobular adenocarcinoma of the breast and adenocarcinoma of stomach of the linitis plastica type. Many effusions associated with cancer may result from an indirect mechanism. This may be an effusion that develops as a result of venous obstruction caused by a neoplasm, or an effusion developing as a result of inflammatory changes, secondary to the presence of a neoplasm. In such effusions neoplastic cells may not be found.

\section{Clinical importance}

The major clinical importance of cytological examination of serous effusions is to establish the presence or absence of malignancy. In case of malignancy the type of the malignancy must be established, so that directed treatment can be started. In an effusion of a patient with a known malignancy it should be established whether it concerns a recurrence or a second primary tumor. Increasingly it is further required to be able to monitor the differentiation or changing expression of cell-biological characteristics (like Her2Neu and estrogen and progesterone receptors in breast cancer) of the tumor. Clinicians should be aware of the importance of adequate information to the pathologist and of optimal sampling.

Nowadays it has become feasible to examine small amounts of serous effusions. Previously, a limited amount of cell material and sub optimal fixation of cell samples restricted the number of stains that could be performed. The process of embedding of a part of the cell samples in agarcyto cell blocks has changed that. Agarcyto blocks enable immunocytochemical and cytochemical staining of identical cells $[12,17]$. It also enables correlation of the morphological and immunocytochemical information of the agarcyto cell blocks with previously removed histological material. Immunocytochemical and cytochemical reactions on agarcyto cell blocks are completely comparable with those of routinely processed tissues. Thus agarcyto cell blocks help to compare morphological, immunocytochemical and cytochemical information and are valuable for optimization of cytological diagnosis of effusions.

\section{Additional techniques}

The contribution by Motherby et al. in this issue of ACP focuses on the contribution of image and flow cy- tometry to establish the absence or presence of DNAaneuploidy in case of primary or secondary malignancy in serous effusions [16]. They point out that the value of routine cytological examination is limited by a relatively low sensitivity of $58 \%$, and that this may be increased to $87.5 \%$ by performing DNA image cytometry, while having a specificity of $100 \%$. Even in case of cytological equivocal effusions the sensitivity was still $75 \%$, at the same specificity. In earlier studies by Decker et al. and Kayser et al. even higher sensitivities were found [7,11]. Decker et al. suggested that cytology should be combined with image DNA cytometry, giving in their study a sensitivity and specificity of $98.5 \%$ and $100 \%$, respectively, [7].

Motherby et al. further demonstrate in this issue of ACP that for the detection of malignancy, DNA image cytometry is far superior to flow cytometry [16]. A low sensitivity of flow cytometry is in agreement with previous findings in fluids $[2,6]$.

In the study by Kayser et al., which showed the results of a prospective, remote image DNA cytometry analysis using the Euroquant server, it was noted that $40 \%$ of effusions did not meet the technical requirements for image DNA cytometry [11]. This is in line with one of the recommendations in the study by Motherby et al. of a strict consideration of the ESACP standards $[11,16]$.

Earlier, DNA image cytometry has been shown to be valuable to discriminate between benign effusions, effusions of patients with a malignant mesothelioma and effusions of patients with a secondary malignancy. Christen et al. [5], Oberholzer et al. [18], and GarciaBonafe et al. [9] have shown in this journal that image analysis of nuclear chromatin texture and nuclear geometry may also help to discriminate between malignant mesothelioma cells and reactive mesothelium cells.

Next to DNA cytometry, immunocytochemistry is increasingly important for examination of serous fluids. Motherby et al. [14,15] demonstrated in two nicely executed studies that a combination of DNAaneuploidy and a positive immunocytochemical reaction with a monoclonal antibody Ber-EP4 may result in an accurate detection and discrimination of metastatic carcinomas and mesotheliomas. Immunocytochemistry has become the most widely used ancillary technique to establish the type of malignancy in serous effusions. Several markers have been described in the literature as important for the discrimination between benign, primary and secondary malignancies in serous effusions. Relevant markers may 
be epithelial markers (cytokeratin 7, 8 and 20, EMA), lymphoid (LCA, CD5, CD15, CD20, CD68, kappa and lambda light chains), mesenchymal (vimentin, desmin) and mesothelial markers (calretinin), as well as other specific biomarkers (CEA, B72.3, Oc125, S100, E-Cadherin, Ber-Ep4, HMB-45, HMFG2, Her$2 \mathrm{Neu}$, estrogen and progestron receptor, chromogranin, thyreoglobuline) $[1,3,4,8,10,19,20,22,24,26]$. Gupta et al. recently described a panel of common immunostains (EMA, CEA, Cytokeratin, B72.3, HMB45, Vimentin, S100, LCA, L26, and kappa and lambda light chains) to be useful in confirming or suggesting the site of the primary tumor [10]. Increasingly it thus has become possible to establish the type of cancer as well as other factors relevant for prognosis. By combining the clinical data, with cytomorphologic and immunocytochemical features it becomes feasible in most cases to discriminate between different malignancies, such as malignant mesothelioma, metastatic adenocarcinoma of the breast, ovary, stomach, colon, kidney, or thyroid, and specific malignancies such as small cell carcinoma, squamous cell carcinoma, sarcoma, Ewing's sarcoma, malignant melanoma, nonHodgkin lymphoma, and Hodgkin's disease.

Also molecular techniques may offer an additional possibility of enhancing the diagnostic accuracy and may provide information regarding the origin of the primary tumor. This may also be applicable when a very limited number of cells or even no intact cells are present as often is the case in cerebrospinal fluids. In a small study we demonstrated that by PCR a leptomeningeal metastasis of a lung cancer could be demonstrated by the presence of a known tumor specific K-ras mutation in the supernatant of a cytological negative CSF [23].

\section{Conclusion}

Accurate diagnosis of a serous effusion mandates the use of ancillary methods such as immunocytochemistry and, as described in this issue of ACP by Moterby et al., by image DNA analysis [16]. The value of flow cytometry for this task is limited [16]. Molecular techniques may aid in an increasingly demanding patient management. Serous effusions should be prepared in such a way that routinely image DNA analysis, immunocytochemistry and molecular techniques can be carried out. Agarcyto cell blocks may become a standard procedure to study series of biomarkers for even small amounts of effusions. These techniques require a high quality of the cell preparation and staining techniques.

\section{References}

[1] J.H. Baars, J.L. De Ruijter, F. Smedts, C.C. Van Niekerk, L.G. Poels, C.A. Seldenrijk and F.C. Ramaekers, The applicability of a keratin 7 monoclonal antibody in routinely Papanicolaoustained cytologic specimens for the differential diagnosis of carcinomas, Am. J. Clin. Pathol. 101(3) (1994), 257-261.

[2] R.H. Bardales, M.W. Stanley, R.F. Schaefer, R.L. Liblit, R.B. Owens and M.J. Surhland, Secondary pericardial malignancies: a critical appraisal of the role of cytology, pericardial biopsy, and DNA ploidy analysis, Am. J. Clin. Pathol. 106(1) (1996), 29-34.

[3] H. Battifora and W.T.E. McCaughey, Tumors of the serosal membranes, in: Atlas of Tumor Pathology, Armed Forces Institute of Pathology, Maryland, 1995.

[4] D.C. Chhieng, H. Yee, D. Schaefer, J.F. Cangiarella, J. Jagirdar, L.A. Chiriboga, J. Jagirdar, L.A. Chiriboga and J.M. Cohen, Calretinin staining pattern aids in the differentiation of mesothelioma from adenocarcinoma in serous effusions, Cancer 25;90(3) (2000), 194-200.

[5] H. Christen, M. Oberholzer, M. Buser, R. Lotscher, R. Gschwind, F. Rosel, R. Ettlin, A. Feess and P. Dalquen, Digital image analy1sis in cytological diagnosis: a morphometric analysis on pleural mesotheliomas, Analyt. Cell. Pathol. 1(2) (1989), 105-122.

[6] C. Cohen, R.J. Tickman, P.B. DeRose and B.P. Whitaker, DNA ploidy studies of benign and malignant tumor: comparison of flow cytometry and image analysis techniques using two types of cytological specimen, Cytopathology 2(5) (1991), 247-259.

[7] D. Decker, H. Stratmann, W. Springer, H. Schwering, N. Varnai and R. Bollmann, Benign and malignant cells in effusions: diagnostic value of image DNA cytometry in comparison to cytological analysis, Pathol. Res. Pract. 194(11) (1998), 791-795.

[8] M.T. Friedman, P. Gentile, A. Tarectecan and A. Fuchs, Malignant mesothelioma. Immunohistochemistry and DNA ploidy analysis as methods to differentiate mesothelioma from benign reactive mesothelial cell proliferation and adenocarcinoma in pleural and peritoneal effusions, Arch. Pathol. Lab. Med. 120 (1996), 959-966.

[9] M. Garcia-Bonafe and A. Moragas, Differential diagnosis of malignant and reactive cells from serous effusions: image and texture analysis study, Analyt. Cell. Pathol. 12(2) (1996), 8598.

[10] R.K. Gupta, D.N. Kenwright, R. Fauck, S. Lallu and S. Naran, The usefulness of a panel of immunostains in the diagnosis and differentiation of metastatic malignancies in pericardial effusions, Cytopathology 11(5) (2000), 312-321.

[11] K. Kayser, S. Blum, M. Beyer, G. Haroske, K.D. Kunze and W. Meyer, Routine DNA cytometry of benign and malignant pleural effusions by means of the remote quantitation server Euroquant: a prospective study, J. Clin. Pathol. 53(10) (2000), 760-764.

[12] H.M.J. Kerstens, J.C.M. Robben, P. Poddighe, W. Melchers, P.C.M. De Wilde, M. Macville and A.G.J.M. Hanselaar, Agarcyto; a novel processing method for multiple molecular diagnostic analyses of cytological samples, J. Histochem. Cytochem. 48(5) (2000), 709-718.

[13] G.L. Koss, Diagnostic Cytopathology and Its Histologic Bases, 1992. 
[14] H. Motherby, N. Friedrichs, M. Kube, B. Nadjari, K. Knops, A. Donner, B. Baschiera, P. Dalquen and A. Bocking, Immunocytochemistry and DNA-image cytometry in diagnostic effusion cytology. II. Diagnostic accuracy in equivocal smears, Analyt. Cell. Pathol. 19(2) (1999), 59-66.

[15] H. Motherby, M. Kube, N. Friedrichs, B. Nadjari, K. Knops, A. Donner, B. Baschiera, P. Dalquen and A. Bocking, Immunocytochemistry and DNA-image cytometry in diagnostic effusion cytology I. Prevalence of markers in tumor cell positive and negative smears, Analyt. Cell. Pathol. 19(1) (1999), 7-20.

[16] H. Motherby, N. Pomjanski, M. Kube, A. Boros, T. Heiden, B. Tribukait and A. Bocking, Diagnostic DNA-flow- vs image cytometry in effusion cytology, Analyt. Cell. Pathol.

[17] B. Naylor, Pleural, peritoneal and pericardial fluids, in: Comprehensive Cytopathology, M. Bibbo, ed., 1991, pp. 541-614.

[18] M. Oberholzer, R. Ettlin, H. Christen, R. Gschwind, M. Buser, F. Rosel, R. Lotscher, P. Dalquen, The significance of morphometric methods in cytologic diagnostics: differentiation between mesothelial cells, mesothelioma cells and metastatic adenocarcinoma cells in pleural effusions with special emphasis on chromatin texture, Analyt. Cell. Pathol. 3(1) (1991), 2542.

[19] J.R. Riera, C. Astengo-Osuna, J.A. Longmate, H. Battifora, The immunohistochemical diagnostic panel for epithelial mesothelioma: a reevaluation after heat-induced epitope retrieval, Am. J. Surg. Pathol. 21(12) (1997), 1409-1419.

[20] F. Roberts, C.M. Harper, I. Downie and R.A. Burnett, Immunohistochemical analysis still has a limited role in the diagnosis of malignant mesothelioma. A study of thirteen antibodies, $A m$. J. Clin. Pathol. 116(2) (2001), 253-262.

[21] M. Salet-van de Pol, A. Hanselaar, Agarcyto cell block technique to improve cytopathological diagnosis, Acta Cytologica.

[22] A.L. Spriggs, M.M. Boddington, G. Austin Gresham, Atlas of Serious Fluid Cytopathology. Current Histopathology, Vol. 14, Kluwer Academic Publishers, 1989.

[23] D.W. Swinkels, J.B. de Kok, A. Hanselaar, K. Lamers, R.H. Boerman, Early detection of leptomeningeal metastasis by PCR examination of tumor-derived K-ras DNA in cerebrospinal fluid, Clin. Chem. 46(1) (2000), 132-133.

[24] I. Thirkettle, P. Harvey, P.S. Hasleton, R.Y. Ball and R.M. Warn, Immunoreactivity for cadherins, $\mathrm{HGF} / \mathrm{SF}$, met, and erbB-2 in pleural malignant mesotheliomas, Histopathology 36(6) (2000), 522-528.

[25] R.W. Veldhuizen, Cytopathologie pleuravocht en ascites, in: Exfoliatieve cytologie, R.W. Veldhuizen and E.C.M. Ooms, eds, Noordwijkerhout, februari 1998, pp. 63-99.

[26] K.D. Wolanski, D. Whitaker, K.B. Shilkin and D.W. Henderson, The use of epithelial membrane antigen and silver-stained nucleolar organizer regions testing in the differential diagnosis of mesothelioma from benign reactive mesothelioses, Cancer 82(3) (1998), 583-590. 


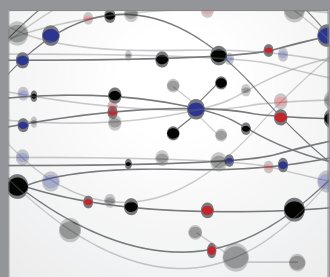

The Scientific World Journal
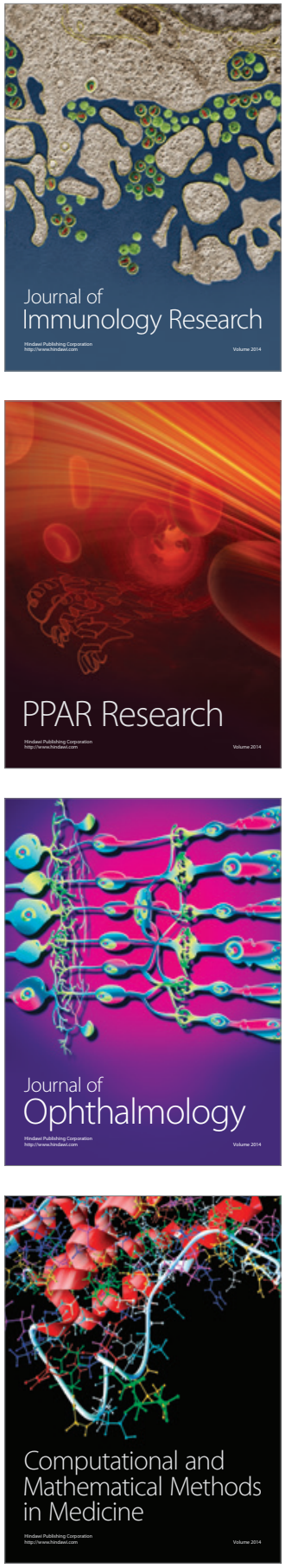

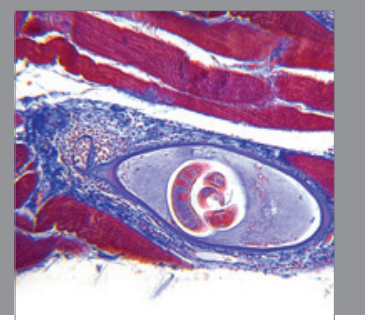

Gastroenterology

Research and Practice
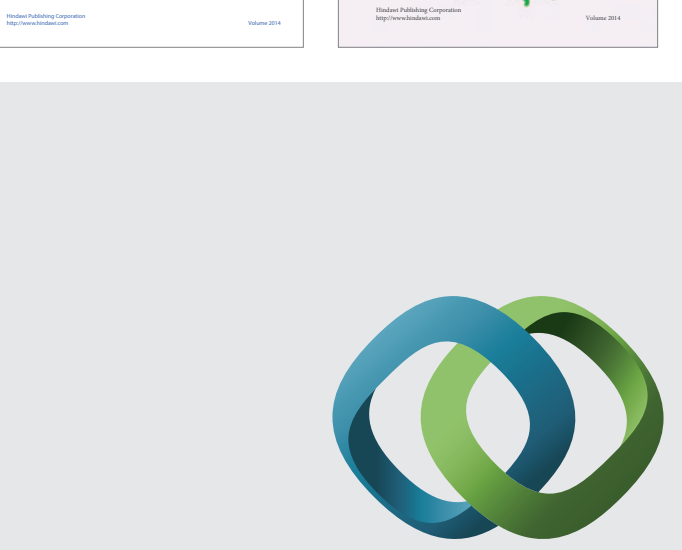

\section{Hindawi}

Submit your manuscripts at

http://www.hindawi.com
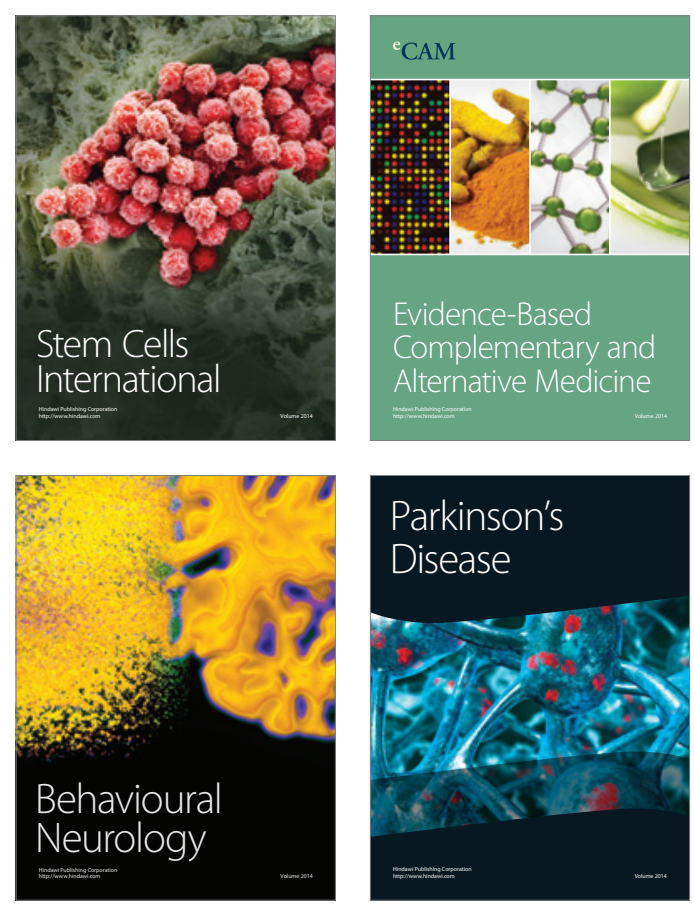

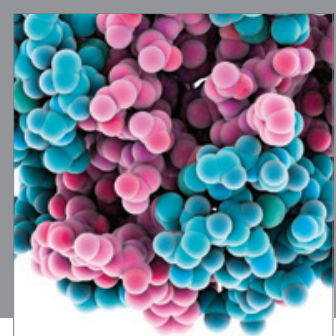

Journal of
Diabetes Research

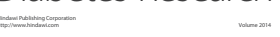

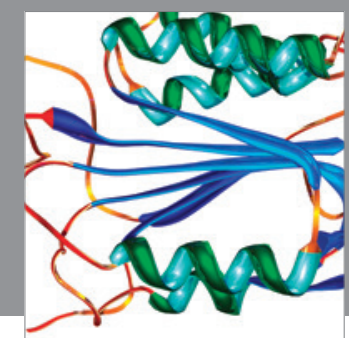

Disease Markers
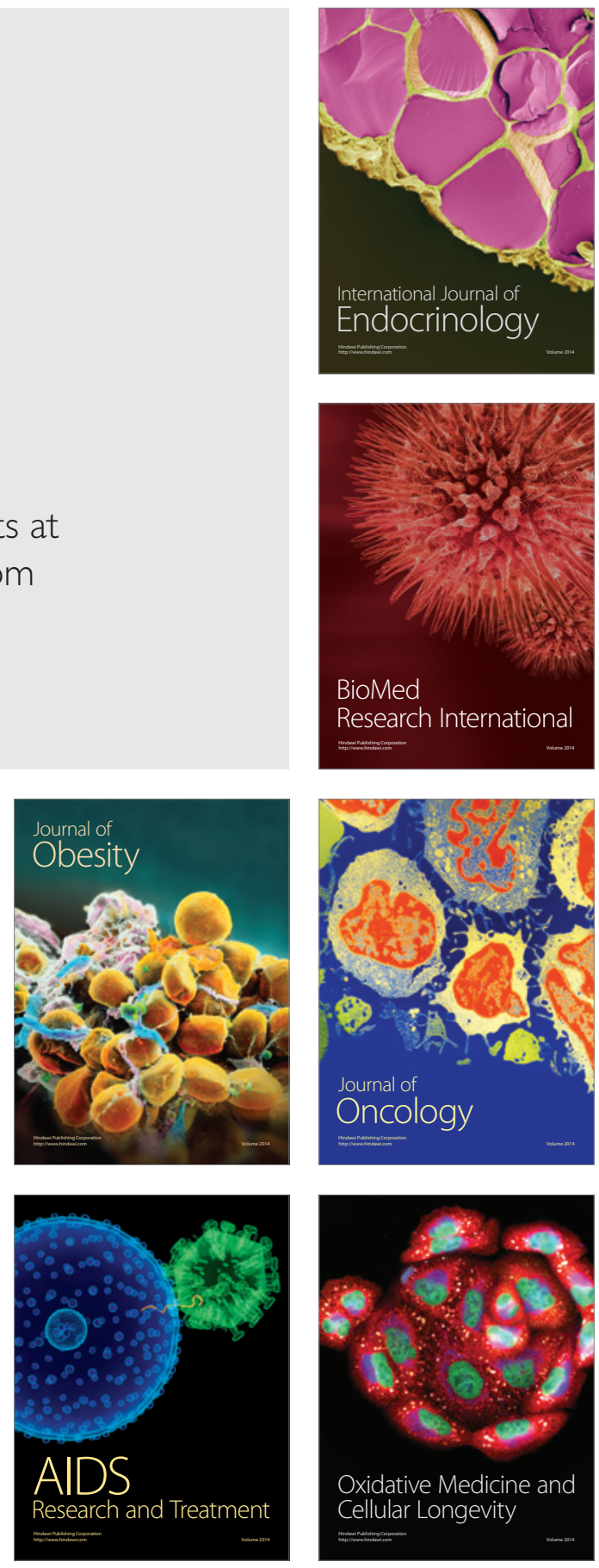